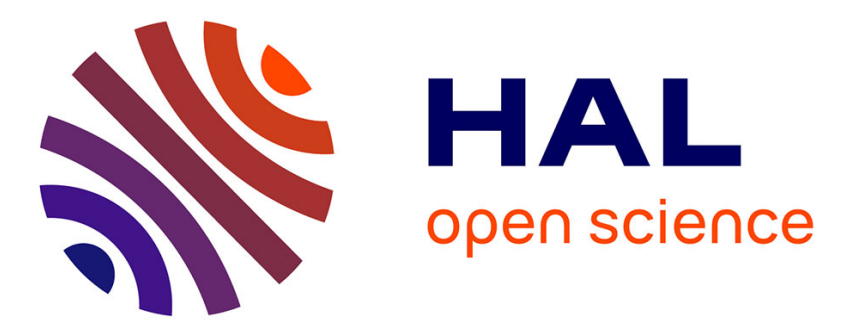

\title{
Detrimental activation of AhR pathway in cancer: an overview of therapeutic strategies
}

Delphine Leclerc, Ananda Christina Staats Pires, Gilles J Guillemin, David Gilot

\section{- To cite this version:}

Delphine Leclerc, Ananda Christina Staats Pires, Gilles J Guillemin, David Gilot. Detrimental activation of AhR pathway in cancer: an overview of therapeutic strategies. Current Opinion in Immunology, 2021, 70, pp.15-26. 10.1016/j.coi.2020.12.003 . hal-03129154

\section{HAL Id: hal-03129154 \\ https://hal.science/hal-03129154}

Submitted on 22 Feb 2021

HAL is a multi-disciplinary open access archive for the deposit and dissemination of scientific research documents, whether they are published or not. The documents may come from teaching and research institutions in France or abroad, or from public or private research centers.
L'archive ouverte pluridisciplinaire HAL, est destinée au dépôt et à la diffusion de documents scientifiques de niveau recherche, publiés ou non, émanant des établissements d'enseignement et de recherche français ou étrangers, des laboratoires publics ou privés. 


\section{Detrimental Activation of AhR Pathway in Cancer: an Overview of Therapeutic Strategies.}

Delphine Leclerc ${ }^{1 *}$, Ananda Christina Staats Pires ${ }^{2,3 *}$, Gilles J. Guillemin ${ }^{2,4 \#}$ and David Gilot ${ }^{1 \#}$

\section{Addresses}

${ }^{1}$ Inserm U1242, Université de Rennes, France; Centre de lutte contre le cancer Eugène Marquis, Rennes, France

${ }^{2}$ Neuroinflammation Group, Department of Biomedical Sciences, Centre for Motor Neuron Disease Research, Faculty of Medicine, Health and Human Sciences, Macquarie University, Sydney, NSW, Australia

${ }^{3}$ Laboratório de Bioenergética e Estresse Oxidativo, Departamento de Bioquímica, Centro de Ciências Biológicas, Universidade Federal de Santa Catarina, Florianópolis, Brasil.

${ }^{4}$ Pandis.org

${ }^{*}$ co-first author

${ }^{\#}$ co-last author

\section{Corresponding author}

David Gilot, (david.gilot@univ-rennes1.fr)

\section{ABSTRACT}

Sustained transcriptional activation of the aryl hydrocarbon receptor (AhR) promotes tumour growth and impairs the immune defence, at least for cutaneous melanoma and glioma. AhR ligands are produced by the tumour microenvironment (TME) and by the tumour itself (intracrine). The recent identification of interleukin-4-induced-1 (IL4I1), a parallel pathway to indoleamine 2 3-dioxygenase 1 (IDO1)/ tryptophan 2,3-dioxygenase (TDO), and its ability to generate AhR ligands, confirms that a complete inhibition of AhR ligand production might be difficult to reach. Here, we have focused on recent discoveries explaining the large varieties of AhR ligands and the functional consequences in terms of cancer cell plasticity and consecutive therapy resistance. We also examined therapeutic strategies targeting the AhR signalling pathway and their possible adverse effects. Since the end of 2019, two phase I clinical trials have investigated the ability of the AhR antagonist to "reset" the immune system and resensitize the cancer cells to therapies by preventing their dedifferentiation.

\section{Highlights}

- $A h R$ is an ubiquitous transcription factor activated by a broad spectrum of endogenous and exogenous ligands.

- Sustained AhR activation promotes immune regulation, cell dedifferentiation and therapy resistance in several cancers.

- Targeting the AhR-signalling pathway might restore therapy efficiency.

- Evaluation of AhR activity in patients' plasma might be a potential associated companion biomarker. 


\section{INTRODUCTION}

The ubiquitous AhR protein belongs to the basic helix-loop-helix/Per-Arnt-Sim (bHLH/PAS) family. AhR (bHLHe76) is widely distributed in tissues and species [1]. It is found in the fruit fly Drosophila melanogaster, the nematode Caenorhabditis elegans, the zebrafish Danio rerio, the pufferfish Takifugu rubripes and other model species, facilitating basic investigations of this bHLH/PAS transcription factor [1,2]. In vertebrates, this receptor has evolved to bind structurally different ligands, including xenobiotics (e.g., aryl hydrocarbons $(\mathrm{AH}))$ [3]. Sustained AhR activation and AhR loss-of-function are deleterious, suggesting that minimal AhR activity is healthy [4-6]. To prevent the deleterious effects of AhR persistent activation, it seems important to consider the diversity of AhR ligands released by bacteria, yeast, fungi, normal and cancer cells, as reviewed in other articles [3,7-10]. Thus, we detailed only the recent findings on AhR ligands and the therapeutic opportunities to short-circuit the AhR signalling pathway.

\section{$\underline{A h R}$, an ubiquitous transcription factor, acts as a sensor}

A wide variety of compounds coming from different sources can be sensed by AhR. Among them, environmental compounds of the halogenated aromatic hydrocarbons (HAH) / polycyclic aromatic hydrocarbon (PAH) family (i.e., 2,3,7,8-tetrachlorodibenzo-p-dioxin (TCDD)) have been thoroughly characterized for their toxic side effects, as we will discuss later [11-13]. Others classes of xenobiotics have been shown to activate AhR [8]. In addition, diet, in particular fruit and vegetable containing flavonoids and indole derivates, represent also an important source of AhR ligands [3,8,9]. Intestinal microflora is also able to generate such ligands: by consuming tryptophan (Trp) coming from diet, they can generate a broad diversity of indole derivates AhR agonists (i.e. indole-3-acetic acid, tryptamine) [9]. Trp can also be degraded by endogenous pathways, especially the kynurenine pathway, which is responsible for $95 \%$ of the Trp degradation [14]. The first step of this pathway consists in the catabolism of tryptophan into the kynurenine agonist by either IDO1, IDO2 or TDO2 enzyme. Kyn can be then converted into downstream metabolites such as kynurenic acid that have also been recently described as an AhR ligand [15]. Even if AhR agonist are numerous, we still probably have not discovered all of them.

Sustained AhR activation by $\mathrm{HAH}$ or $\mathrm{PAH}$, such as TCDD or polycyclic aromatic hydrocarbon, in mice and rats, leads to a broad spectrum of adverse effects, including cancer development and the impairment of endocrine functions and immunity. TCDD also has deleterious effects on human health [11-13], although humans seem to be more resistant to dioxins than rodents. The mice lacking $A h R$ expression $\left(A h R^{(--)}\right)$clearly demonstrated the critical role of AhR in this pollutant-induced toxicity and carcinogenesis [16].

Surprisingly, these mice display impaired vascular differentiation, low fertility and liver and immune system abnormalities [17]. This receptor therefore seems to be essential for both normal development $[18,19]$ and almost all the deleterious effects of TCDD [20,21]. To date only three young patients from a consanguineous Christian Arab family from Northern Israel have been described with a stop mutation in the $A h R$ gene, abrogating AhR protein expression (c.1861C>T;p.Q621*). Interestingly, these three children have the same eye movement disorder [5] as observed in $\mathrm{AhR}^{(-/)}$mice. These studies also suggest the physiological roles of endogenous AhR ligands.

$\mathrm{AH}$ toxicity seems to essentially result from the deregulation of gene expression induced by AhR activation [12,21]. According to the canonical activation model (Fig. 1A), cytosolic AhR is translocated to the nucleus after ligand binding. It then dissociates from a chaperone complex and forms a heterodimer with the aryl hydrocarbon receptor nuclear translocator (ARNT). The AhR/ARNT complex binds to specific xenobiotic-responsive 
elements (XRE) (core sequence: 5'-GCGTG-3') [22] in the promoters of target genes, thereby regulating their transcription [23].

Typically, the AhR pathway is transiently activated in order to eliminate the inducer molecule (defined as the ligand). It is coupled to a negative feedback system based on the transcriptional induction of the AhR repressor (AhRR), leading to AhR-ARNT dimer dissociation and AhR degradation by the $26 \mathrm{~S}$ proteasome [24,25], corresponding to the 'stop signal' (OFF on Fig. 1A). This loop is transiently activated due to AhR proteasomal degradation, preventing the long-term activation of the AhR pathway. AhR transcription and de novo protein synthesis ultimately result in a return to basal AhR levels (Fig. 1B, AhR cycle). Expression of CYP1A1 mRNA and protein is rapidly induced in order to promote the elimination of the AhR ligand. CYP1A1 induction is transient, because the half-lives of CYP1A1 mRNA and protein are very short $(<10 \mathrm{~h}$ and $<5 \mathrm{~h}$, respectively), whereas the half-life of unbound AhR protein is much longer ( $>48 \mathrm{~h}$ ) [26]. The combination of these phenomena leads to the elimination of the AhR ligands protecting the cell. However, the AhR pathway fails to eliminate TCDD: the half-life of TCDD is usually two to four weeks in rodents $[27,28]$, but it has been estimated at seven to eleven years in humans [29]. This persistent pollutant profoundly modifies the gene expression profile through a sustained AhR activation resulting in deleterious effects in human.

A sustained AhR activation can be reachable via endogenous ligands. In contrast to TCDD, the different endogenous ligands are all eliminated by the XME system [3]. So, to reach a sustained AhR pathway activation, the tumour and/or its environment should produce an astonishing quantity of AhR ligands or/and impair their elimination [30]. The Kyn, a metabolite derived from the IDO1/TDO2 catabolism of Trp, is an endogenous AhR ligand produced by cancer cells [9]. In cutaneous melanoma, the exact quantification of Kyn is not clearly defined but it is estimated to $>50 \mu \mathrm{M}$ in the TME (and 2-8 $\mu \mathrm{M}$ in plasma depending on cancer type [3135]). This Kyn concentration inside the cutaneous melanoma may explain the failure of clinical trials in phase III (based on IDO1 inhibition). Other inhibitors preventing Kyn production have been conceived but neurological disorders (in mice) disrupted their clinical developments [36].

Several clinical trials with IDO1 and TDO inhibitors reported that totally blocking the initial step of the Kyn pathway could trigger some adverse effects associated with the nonspecific activation of AhR or mTOR that can induce inflammatory signalling or growth pathways. Some of the Trp analogues can be recognised by gut bacteria and be associated with Trp depletion [37]. These results suggest that Kyn or its derivatives are essential for brain functions and homeostasis. In the brain, Kyn is mostly produced by astrocytes [38] and these glial cells' main roles are to maintain the central nervous system homeostasis and to regulate immune response.

Other neurological diseases also generate similar high levels of this AhR ligand. We previously showed that Kyn levels are elevated in the serum and cerebrospinal fluid of patients with Alzheimer's disease, multiple sclerosis, motor neuron disease, and several other neuroinflammatory conditions [39]. Interestingly, the astroglial expression of AhR increases with age and is much higher in Alzheimer's patients [40].

\section{AhR signature}

Many groups have attempted to identify AhR target genes (AhR signature) to assess the detrimental activation of AhR in humans. Despite extensive analyses including data from $A h R^{(--)}$mice, neither the core XRE sequence (5'-GCGTG-3') nor the variant response element XRE-II (5-CATG(N) ${ }_{6} \mathrm{C}[\mathrm{T} \mid \mathrm{A}] \mathrm{TG}-3$ ), which binds AhR [41], are particularly abundant in the promoters of genes deregulated in response to AhR ligand exposure [21,41]. These experiments strongly suggest that AhR-modulated genes are not all directly governed by AhR (on their promoters). Despite the poor correlation between the presence of a XRE sequence in the promoter and inducibility by AhR ligands, several genes, including TIPARP and CYP1A1, are considered to be AhR targets [21] for many decades.

Recently, Opitz's team looked for a pan-tissue AhR signature by performing weighted gene co-expression network analysis across the 32 TCGA tumours. They established an 
unmatched AhR signature (166 genes) containing the classical AhR target genes (TIPARP, CYP1A1, CYP1B1, AhRR and AhR). Among them, authors identified the L-amino acid oxidase IL4I1 as a new AhR target gene. The functional validation of IL4I1 as a new source of AhR ligands demonstrates the robustness of these analyses [15]. In addition, Corre and collaborators also established an AhR signature, but it was restricted to the cutaneous melanoma cells. To establish this signature, we used publicly available AhR ChIP-seq data [42]. We demonstrated that a sustained AhR activation rewired gene expression in these tumour cells, promoting cell plasticity and therapy resistance (AhR signature and therapy resistance signature). By comparing these two signatures [15,42], we confirm here that CYP1A1, CYP1B1, TIPARP and THBS1 are good indicators for tracking AhR activation (Fig. $1 \mathrm{C})$.

The exact sequence required for AhR binding onto promoters is probably more complex than initially thought since AhR can interact with different partners probably on different sequences. AhR has been found in several protein complexes, but little is understood about the interaction of AhR with other transcription factors such as Sp-1 [43-46], RelB [47], Rb [48], RelA [49,50], COUP-TF [51], ER [44,52], SLUG [53], c-Maf [54-57], Egr-1 [58], AP-2 [58], USF-2 [58], Stat1 [59,60] and Stat5 [59]. AhR has been found as part of a complex with Egr-1 and activator protein-2 on the THBS1 promoter [58], and with Stat1 and Stat5 in the negative regulation of Th17 development [59]. Two other groups have reported that c-maf binds to AhR to regulate the immune response in mice and humans. AhR acts in synergy with c-maf to promote the development of type 1 regulatory T cells (Tr1 cells), which produce interleukin 10 (IL-10), an anti-inflammatory cytokine involved in preventing tissue inflammation, autoimmunity and graft-versus-host disease. AhR has been shown to bind to c-maf, promoting the transactivation of the //10 and I/21 promoters, resulting in the generation of Tr1 cells [61] and improvements in the symptoms of experimental autoimmune encephalomyelitis [62]. The binding site of the AhR/c-maf dimer was not clearly identified in these studies or in studies of other partners of AhR. These heterodimers (AhR + a partner) probably bind to different response elements from the complex formed by AhR and ARNT (HIF1 $\beta$ ) in response to xenobiotics (XRE). We therefore believe that single cell RNA-sequencing analyses coupled to CRISPR-Cas9 experiments will define the exact partners of AhR and their respective target genes.

\section{AhR drives cell dedifferentiation and therapy resistance}

The $A h R^{(--)}$mice studies revealed that $A h R$ is involved in many processes including cell differentiation $[6,16,17]$. To illustrate this point, AhR is now considered as a master gene for polarisation of normal immune cells [63,64]. For cancer cells, we demonstrated that sustained AhR activation promotes melanoma cell dedifferentiation by stimulating a mesenchymal state associated to therapy-resistance. As proof-of-concept, we showed that the AhR antagonist restored BRAF inhibitor sensitivity and strongly reduced the number of persister cells (i.e., BRAFi-resistant cells, source of relapse) [42]. In 2011, Opitz et al. demonstrated a sustained AhR activation by Kyn in glioma. TDO2-derived Kyn suppresses antitumour immune responses and promotes tumour-cell survival and motility through the AhR in an intracrine/paracrine fashion. As described for the cutaneous melanoma, distinct differentiation states have been characterised for glioblastoma (GBM) (pro-neural, classical, and mesenchymal GBM) [65]. In our latest manuscript we found that the SMAD3-signature overlaps with the mesenchymal GBM signature [66]. Mesenchymal GBM are the most aggressive GBM and are usually associated with poor overall survival $[65,67,68]$. Altogether, these studies suggest that sustained AhR activation is associated with cancer aggressiveness and cell plasticity.

Four recent publications demonstrated the melanoma cell plasticity in response to therapies, explaining the intratumour heterogeneity (ITH) during the relapse [69-72]. This plasticity looks like to an epithelial-mesenchymal transition (EMT). However, we define here this transition as an "onco-EMT" since EMT is defined for normal cells and melanoma cells are not epithelial cells. scRNA-seq demonstrated that ITH is also found prior the treatment for 
melanoma and glioma, suggesting that different cell differentiation states co-exist in the tumour (Fig. 2A). This could be a result of clonal evolution (additional genetic alterations) and/or cell plasticity (onco-EMT) (Fig. 2B). Similar results have been collected from scRNA-seq experiments in glioma [67]. In accordance with these descriptive studies, we recently demonstrated that differentiated melanoma cells can be redirected into a dedifferentiated state using the potent AhR ligand TCDD [42]. So, we propose that AhR participates with the ITH.

Until now, it has been difficult to give a clear answer on how the AhR signalling pathway promotes the dedifferentiation. AhR-signature is mainly based on gene expression correlation suggesting that several genes are not directly driven by AhR but by other downstream transcription factors. Recently, we investigated the downstream factors of the AhR pathway in melanoma cell plasticity and therapy resistance [66]. We identified mothers against decapentaplegic homolog 3 (SMAD3), as a downstream target gene of AhR. SMAD3 induction by AhR has been recently confirmed by Sadik et al. 2020 [15]. The consecutive increase of SMAD3 transcriptional activity promotes a mesenchymal-like phenotype and BRAFiresistance by acting as an upstream transcriptional regulator of potent BRAFi-resistance genes such as EGFR and $A X L$. This SMAD3-signature predicts resistance to both current melanoma therapies in different cohorts. Critically, chemical inhibition of SMAD3 may constitute an amenable target for melanoma since it efficiently abrogates 'persister cells' survival (Fig. 3 \& 4). It is noteworthy that cutaneous melanoma cells are able to produce TGF- $\beta$, which in turn activates SMAD3 [73]. In addition, the TGF- $\beta$ can be released from the Treg cells [74,75]. Soluble TGF- $\beta$ in the TME in turn inhibits antigen-presenting cells and effector T cells, indirectly favouring the tumour growth. This cytokine also induces a mesenchymal-like phenotype of cancer cells, promoting the migration, invasion capability and consequently the metastases.

The Fernandez-Salguero team demonstrated that AhR drives NANOG and OCT4 expression via a retrotransposon-regulated mechanism, promoting the dedifferentiation process. This unexpected mechanism may also, in part, explain the dedifferentiation induced by AhR agonists [76].

Altogether, these studies confirmed that AhR signature may contain indirect targets (i.e., genes driven by SMAD3). Moreover, we better understand why XRE motifs are not always found on promoters of genes creating the AhR signature. The improved description of the AhR signalling pathway opens new opportunities to limit AhR deleterious effects.

\section{The waltz of AhR ligands}

Cancer cell dedifferentiation could be accomplished by AhR ligands or indirectly, by cytokines stimulating their production/release. The Huang team demonstrated that the cytokine IFN- $\gamma$, produced by CD8+ T cells, induces dormancy of dedifferentiated melanoma cells via Kyn $[77,78]$. The Kyn production requires the induction of IDO1 in dedifferentiated cancer cells. In contrast, this cytokine provokes the cell death of differentiated melanoma cells. Kyn is transferred into CD8+ T cells and upregulates PD-1. Thus, by combining IFN- $\gamma$ and the AhR antagonist, they abrogated the tumour growth from the dormant cells. AhR blockade enhances adoptive T cell therapy efficacy in a mouse melanoma model.

This study also highlighted the importance of the Kyn and Trp transporters for the deleterious activation of AhR. To date, these transporters have been involved in Kyn and Trp transport (SLC1A5 and SLC7A5) $[78,79]$ and may represent remarkable targets to limit AhR ligand accumulation in cancer cells and T cells (Fig. $3 \& 4$ ). It would be interesting to define the transporters of AhR ligands in general since the ligand family is growing. Moreover, as a part of the AhR ligand is lipophilic [3]; they are able to cross the lipid bilayer without the need of transporters. CRISPR-Cas9 screening may improve our knowledge of AhR ligand transporters and pave the route to new therapeutic strategies

Even if a sustained activation of AhR is revealed in dedifferentiated cells (melanoma \& glioblastoma), the nature of ligand(s) inducing this deleterious effect remains poorly studied. 
Two hypotheses are credible, but they are not mutually exclusive: a high systemic or a high local concentration of AhR activators.

A high systemic concentration of an AhR ligand may stimulate AhR activity in many cells including tumour cells as already published for Kyn and other Trp derivatives [31,80]. A particular microbiota, generating a high level of indoles, may also be incriminated [3,7-9]. It is interesting to note that response to immune checkpoint therapy depends to endogenous microbiota at least in cutaneous melanoma. To date, the indoles generated by these specific bacteria have not been identified to be able to activate AhR in tumours $[81,82]$. A special food regimen, enriched in flavonoids or $\mathrm{HAHs}$ and/or PAHs, might also stimulate AhR activity. However, this hypothesis suggests that the patient must consume this food daily since the halflife of these AhR activators is short except for TCDD $[17,29]$. Another possible explanation relies on a default of AhR activator metabolism, leading to a sustained AhR activation as suggested for FICZ $[30,83]$.

A high local concentration of AhR activators suggests that normal cells from the TME or the tumour cells themselves expressed a specific enzyme. It has been recently published for IL4L1 [15] expressed by tumour supportive monocytes. An alternative hypothesis may involve an enzyme expressed by the tumour cells and this protein might produce an endogenous AhR activator directly from the cancer cell (intracrine production) or by consuming a precursor taken from the blood (autocrine production). It is important to keep in mind that several bacteria have been identified into different tumours [84]. To date, the role of these bacteria remains unsolved. It is tempting to postulate that these bacteria might continuously generate AhR ligands as for the bacteria from the microbiota [85]. To conclude, the characterization of AhR endogenous ligands in cancer cells and TME remains an important field of investigation for the next decade.

\section{Perspectives}

Prevention of sustained AhR pathway activation is an exciting target for cancer therapy. To abolish this deleterious AhR activation, researches have tried to reduce AhR ligand production by limiting the release of Trp metabolites. However, the clinical trials, based on IDO inhibition, have failed in phase III (ECHO-301/KN-252), probably due to the existence of other pathways generating AhR ligands such as IL4I1. Moreover, it is clear nowadays that several cancer cells are able to produce AhR ligands to activate their own AhR (Fig. 3, Intracrine (Intra)). Thus, strategies aiming to reduce the systemic Kyn concentration are interested in decreasing the deleterious effect on immune cells and on cells from the TME. However, IDO/TDO inhibitors probably act only on one activator (not directly on cancer cells). Despite this drawback, the Georgiou team demonstrated that the recombinant kynureninase (KYNU; catalysing the degradation of Kyn into the anthranilic acid) is remarkably effective, not only by restoring antitumour immune response in mice, but also by improving median survival [86]. However, it is important to note that recombinant KYNU can drive the production Kyn metabolites that are AhR ligands (i.e., 3-hydroxyanthranilic acid and its product cinnabarinic acid) [15,87-89].

Nevertheless, given the multifactorial origin and availability (exogenous (Exo) and intracrine (Intra)) of AhR ligands for the tumour (Fig. 3), we believe that a chemical inhibition of the AhR signalling pathway is probably the best way to target both cancer cells and immune cells. Several AhR antagonists have been recently developed and recently reviewed [8,90-94] (Box 1). Promising pre-clinical results were obtained with the AhR antagonists Kyn101 (Ikena Oncology) [90], PX-A24590 (Phenex Pharmaceuticals) [91] and HP163 (Hercules Pharmaceuticals) [92]. In addition, two candidates are currently under phase I clinical trials (IK175 from Ikena Oncology and BAY2416964 from Bayer).

Even if we have to wait for the results of these two clinical trials to make a conclusion on this strategy (clinical trial ID NCT04200963 and NCT04069026), it is important to keep in mind that paradoxically, AhR activation by aminoflavone (AhR agonist) in vitro and in mouse xenograft models exerts anti-tumour properties, especially in the human breast cancer cell line MCF-7 and in human renal cancer cells lines $[95,96]$. These contradictory results demonstrate 
that AhR can mediate both pro- or anti-tumoural responses depending of the cellular context, thereby showing the complexity of targeting AhR activity. Moreover, AhR knock-out mice display serious defects [16]. Altogether, these studies suggest that severe adverse effects may occur during these two clinical trials. It could be interesting to address the clinical relevance of strategies aiming to inhibit downstream targets of the AhR signalling pathway such as SMAD3 (since SMAD3 knock-out mice are not severely impacted as observed in the AhR knock-out ones). To overcome the potential unanticipated effects mediated by AhR antagonists, AhR inhibition could be achieved using antisense oligonucleotides (ASO) depleting AhR mRNA (or $S M A D 3$ ). The ASO strategy has been successfully used in cutaneous melanoma (PDX models) by targeting the IncRNA SAMMSON or TYRP1 mRNA [97,98]. Interestingly, ASOs mediate a "partial knock-down", avoiding the serious defects observed in knock-out mice.

As recently reviewed $[4,7,10]$, the AhR ligands are numerous and probably not all identified in humans. This suggests that a global estimation of AhR ligand in the plasma may be interesting for choosing a therapy based on the AhR antagonist. However, it is highly probable that an intracrine AhR ligand production (by cancer cells) may also exist. Moreover, several AhR ligands are probably not able to cross the lipid bilayer. Thus, the AhR activity assessment in plasma could be incomplete but informative. Since AhR ligands are not all known, the test could be based on XRE-Luc assay or AhR nuclear translocation, methods estimating both agonists and antagonists of AhR $[99,100]$ directly from the plasma.

To conclude, we believe that the refinement of AhR pathway inhibition will be based on a better understanding of the AhR signalling pathway and intracrine AhR ligand production by tumour cells and TME. These findings will pave the route to new therapeutic strategies. 


\section{Conflict of interest statement}

Nothing declared.

\section{Acknowledgements}

Ms Leclerc is funded by the Ministère de l'Enseignement Supérieur, de la Recherche et de I'Innovation (PhD fellowship). D. Gilot is funded by Ligue National Contre le Cancer (LNCC), Plan Hubert Curien FASIC and Plan Cancer Inserm (ITMO Aviesan 2020). Prof Guillemin is funded by the National Health and Medical Research Council (NHMRC), PANDIS, Tour de cure foundation and Fight on the Beaches Foundation. Ms Staats Pires is funded by Coordenação de Aperfeiçoamento de Pessoal de Nível Superior (CAPES) and International Cotutelle Macquarie University Research Exellence Scholarship (Cotutelle "iMQRES"). The figures were created with BioRender.com. This manuscript has been professionally edited by Redfern Communication, Australia.

BOX 1:

Gene signature:

Information about the activity of a specific group of genes in a cell or tissue. In cancer, gene signatures can show how likely certain types of cancer are to grow and spread in the body or how likely they are to recur. A gene signature may be used to help diagnose disease such as cancer, plan treatment, find out how well treatment is working, and make a prognosis.

Retrieved September 252020 from https://www.cancer.gov/publications/dictionaries/cancer-terms/def/gene-signature

\section{Antagonist:}

A substance that partially or completely nullifies the effect of another agent; a chemical entity that is not naturally found in the body which occupies a receptor, produces no physiologic eff ects and prevents endogenous and exogenous chemicals from producing an effect on that re ceptor.

Inhibitor:

An agent that restrains or retards physiologic, chemical, or enzymatic action.

Retrieved September 152020 from https://medical-dictionary.thefreedictionary.com/inhibitor

\section{Figure 1: AhR, a sensor to adapt the cell to the stress signal}

A- AhR is sequestered in the cytosol with chaperones and immunophilin-like protein, in the absence of ligand. In the presence of ligand, AhR is translocated to the nucleus, where it dissociates from the chaperone complex and forms a heterodimer with the AhR nuclear translocator (ARNT). This heterodimer binds to specific xenobiotic responsive elements (XRE) found in the promoters of target genes, thereby regulating the transcription of these genes (AhR signature). In this way, TCDD and other AhR agonists markedly induce the expression of xenobiotic-metabolising enzymes (XME, phases I and II), including CYP1A1, which is known to detoxify (but also, in some cases, to bioactivate) carcinogens. Metabolites are then eliminated in body fluids, such as blood, plasma, urine and faeces. The feedback loop facilitates the rapid degradation of activated AhR by the proteasome, preventing the sustained AhR activation. De novo synthesis of the AhR protein restores the ability of the cell to respond to a new ligand.

B- The diagram shows the theoretical response of the cell to ligand exposure. The ligand binds to $A h R$, inducing its translocation, the transcription of XME genes and the proteasomal 
degradation of AhR. AhR transiently induces the production of CYP1A1 mRNA and protein and the transcription of its own gene, resulting in the renewal of AhR protein within the cell. The kinetics of this process depends on the concentration of the ligand and its affinity for AhR. C- The AhR signature. A Venn chart comparing three signatures established by Sadik et al., Cell 2020 and Corre et al. Nature Communications 2018. The last signature (AhR and Resistance) corresponds to a mixture of two signatures (AhR associated genes in cutaneous melanoma and genes associated to BRAF inhibitor resistance). TIPARP, THBS1, CYP1A1 and CYP1B1 are common to the three signatures. (AhR) Aryl hydrocarbon receptor; (AhRR) AhR repressor protein; (CYP1A1) cytochrome P4501A1; (CYP1B1) cytochrome P4501B1; (TCDD) 2,3,7,8-tetrachlorodibenzo-p-dioxin; (TIPARP) TCDD Inducible Poly(ADP-Ribose) Polymerase; (THBS1) Thrombospondin 1.

\section{Figure 2: Tumour cell plasticity in response to therapy}

A- A scheme illustrating the plasticity of differentiated cancer cells (cutaneous melanoma or glioma cells) in response to therapy (i.e., BRAF inhibitor (BRAFi) for melanoma). Typically, under BRAFi pressure, death of BRAFi-sensitive cells (differentiated) leads to an enrichment of a small sub-population of AhR-activated and BRAFi-persister cells, responsible for relapse. At the end of the treatment, dedifferentiated cells can restart a differentiation process, which is associated with therapy sensitivity. This differentiation cycle is independent of genetic alterations.

B- A scheme illustrating the occurrence of genetic alterations during the differentiation/dedifferentiation cycle of tumour cells. These genetic alterations take place at any steps of the cycle (differentiated cells, stressed cells and undifferentiated cells). These two events (differentiation cycle and possible genetic alterations) may explain the intratumour heterogeneity.

\section{Figure 3: The waltz of AhR ligands}

A scheme illustrating the diversity of AhR ligands and the uptake and export of these molecules defined here as a waltz. Intracellular ligands come from two sources (exogenous (Exo) and intracrine (Intra)) in cancer cell. Ligand-activated AhR drives gene expression (AhR signature). AhR activation promotes IDO1 and IL4I1 gene expression; two enzymes able to generate AhR ligands. It is important to note that IL4I1 can be secreted in the tumour microenvironment to generate AhR ligands outside the cancer cell. Moreover, IL4I1 is expressed/secreted by other cell types such as macrophages (M $\varnothing$ ) associated with the tumour. In contrast to IL4I1, IDO1 increases the amount of AhR ligand inside the cancer cell. So, the AhR ligand concentration in the cancer cell depends on the ability of the cancer cell to produce the AhR ligand but also on the microenvironment. Transporters are key regulators of AhR ligand concentration in cancer cells since they import the AhR ligand and precursors such as tryptophan (Trp). On the other hand, transporters are also able to export the AhR ligand to target the cells located in the tumour microenvironment. To add a level of complexity, studies have demonstrated that an interaction is established between the microenvironment and the cancer cells. For example, the TGF- $\beta$ can be produced by the cancer cell itself and this cytokine can activate the TGF- $\beta$ signalling pathway (increasing the activity of SMAD3 transcription factor, which contributes to the AhR signature) on cancer cells, cancer-associated fibroblasts (CAF), myeloid-derived suppressor cells (MDSCs) and on CD8 lymphocytes (CD8+T cells). These lymphocytes are able to release interferon gamma (IFN- $\gamma$ ), which promote the cancer cell plasticity and IDO1 expression. The lifestyle (TCDD and PAHs) and microbiota participate to increase AhR ligands in plasma. It is noteworthy that several AhR ligands are able to cross the cell membrane since they are lipophilic. This scheme recapitulates, at least in part, the relationship between AhR signature and cancer cell plasticity in its environment. (AhR) aryl hydrocarbon receptor; (AhRR) AhR repressor protein; (XRE) xenobiotic responsive elements; (IDO) indoleamine 23 dioxygenase; (IL4I1) interleukin-4-induced-1; (TCDD) 2,3,7,8-tetrachlorodibenzo-p-dioxin; (TGF- $\beta$ ) Transforming growth factor beta; (TGF- $\beta$ R) TGF- $\beta$ receptor; (IFN- $\gamma R$ ) IFN- $\gamma$ receptor; (EGFR) epidermal growth factor receptor; (SMAD3) mothers against decapentaplegic 
homolog 3; (SLC745) solute carrier family 7 member 5; (STAT) signal transducer and activator of transcription; (ERK) extracellular signal-regulated kinase.

\section{Figure 4: How to shut down the AhR signalling pathway?}

A scheme recapitulating the main strategies targeting the AhR signalling pathway. The IDO/TDO inhibitors have been already evaluated in clinical trials (failure in phase III for IDO1 inhibitor). Two clinical trials based on AhR antagonists started in December 2019. The recombinant kynureninase (KYNU) showed promising effects in preclinical studies. To the best of our knowledge, no efficient IL4I1 inhibitor has been described and ASOs targeting AhR or SMAD3 have not be evaluated as anticancer strategies. The tryptophan (Trp) and kynurenine (Kyn) pathway metabolite transporters are not well described. So, the specificity of available inhibitors can be investigated. (AhR) aryl hydrocarbon receptor; (AhRR) AhR repressor protein; (XRE) xenobiotic responsive elements; (IDO) indoleamine 2 3-dioxygenase; (TDO) tryptophan 2,3-dioxygenase; (IL4I1) interleukin-4-induced-1; (ASO) antisense oligonucleotides; (SMAD3) mothers against decapentaplegic homolog 3.

\section{References and recommended reading}

Papers of particular interest, published within the period of review, have been highlighted as:

- of special interest

$\bullet \bullet$ of outstanding interest.

1. Hahn ME: Aryl hydrocarbon receptors: diversity and evolution. Chem Biol Interact 2002, 141:131-160.

2. Hahn ME: The aryl hydrocarbon receptor: a comparative perspective. Comp Biochem Physiol C Pharmacol Toxicol Endocrinol 1998, 121:23-53.

3. Denison MS, Nagy SR: Activation of the aryl hydrocarbon receptor by structurally diverse exogenous and endogenous chemicals. Annu Rev Pharmacol Toxicol 2003, 43:309-334.

4. Safe S, Jin Uh, Park H, Chapkin Rs, Jayaraman A: Aryl Hydrocarbon Receptor (AHR) Ligands as Selective AHR Modulators (SAhRMs). Int J Mol Sci 2020, 21.

- This review described the selective AhR modulators, a class of AhR ligands exhibiting selectively an agonist, antagonist or partial agonist activity. This activity depends on the cellular context.

5. Mayer AK, Mahajnah M, Thomas MG, Cohen Y, Habib A, Schulze M, Maconachie GDE, AlMoallem B, De Baere E, Lorenz B, et al.: Homozygous stop mutation in AHR causes autosomal recessive foveal hypoplasia and infantile nystagmus. Brain J Neurol 2019, 142:1528-1534.

6. Takenaka MC, Gabriely G, Rothhammer V, Mascanfroni ID, Wheeler MA, Chao C-C, Gutiérrez-Vázquez C, Kenison J, Tjon EC, Barroso A, et al.: Control of tumorassociated macrophages and $\mathrm{T}$ cells in glioblastoma via AHR and CD39. Nat Neurosci 2019, 22:729-740. 
7. Bock K: Aryl hydrocarbon receptor (AHR) functions: Balancing opposing processes including inflammatory reactions. Biochem Pharmacol 2020, 178.

8. Murray IA, Patterson AD, Perdew GH: AH RECEPTOR LIGANDS IN CANCER: FRIEND AND FOE. Nat Rev Cancer 2014, 14:801-814.

9. Hubbard TD, Murray IA, Perdew GH: Indole and Tryptophan Metabolism: Endogenous and Dietary Routes to Ah Receptor Activation. Drug Metab Dispos Biol Fate Chem 2015, 43:1522-1535.

10. Ghiboub M, Verburgt CM, Sovran B, Benninga MA, de Jonge WJ, Van Limbergen JE: Nutritional Therapy to Modulate Tryptophan Metabolism and Aryl HydrocarbonReceptor Signaling Activation in Human Diseases. Nutrients 2020, 12.

11. Bunger MK, Moran SM, Glover E, Thomae TL, Lahvis GP, Lin BC, Bradfield CA: Resistance to 2,3,7,8-tetrachlorodibenzo-p-dioxin toxicity and abnormal liver development in mice carrying a mutation in the nuclear localization sequence of the aryl hydrocarbon receptor. J Biol Chem 2003, 278:17767-17774.

12. Fernandez-Salguero PM, Hilbert DM, Rudikoff S, Ward JM, Gonzalez FJ: Arylhydrocarbon receptor-deficient mice are resistant to 2,3,7,8-tetrachlorodibenzo-pdioxin-induced toxicity. Toxicol Appl Pharmacol 1996, 140:173-179.

13. Mimura J, Yamashita K, Nakamura K, Morita M, Takagi TN, Nakao K, Ema M, Sogawa $\mathrm{K}$, Yasuda M, Katsuki M, et al.: Loss of teratogenic response to 2,3,7,8tetrachlorodibenzo-p-dioxin (TCDD) in mice lacking the Ah (dioxin) receptor. Genes Cells Devoted Mol Cell Mech 1997, 2:645-654.

14. Badawy AA-B: Kynurenine Pathway of Tryptophan Metabolism: Regulatory and Functional Aspects. Int J Tryptophan Res IJTR 2017, 10.

15. Sadik A, Somarribas Patterson LF, Öztürk S, Mohapatra SR, Panitz V, Secker PF, Pfänder P, Loth S, Salem H, Prentzell MT, et al.: IL4I1 Is a Metabolic Immune Checkpoint that Activates the AHR and Promotes Tumor Progression. Cell 2020, 182:1252-1270.e34.

- This study identified the enzyme IL4I1 as a source of AhR ligands via tryptophan catabolism. It may explain the failure of the clinical trial ECHO-301/KN-252 based on IDO inhibition.

16. Gonzalez FJ, Fernandez-Salguero P: The aryl hydrocarbon receptor: studies using the AHR-null mice. Drug Metab Dispos Biol Fate Chem 1998, 26:1194-1198.

17. Denison MS, Soshilov AA, He G, DeGroot DE, Zhao B: Exactly the same but different: promiscuity and diversity in the molecular mechanisms of action of the aryl hydrocarbon (dioxin) receptor. Toxicol Sci Off J Soc Toxicol 2011, 124:1-22.

18. Murray Ia, Perdew Gh: Ligand activation of the Ah receptor contributes to gastrointestinal homeostasis. Curr Opin Toxicol 2017, 2. 
19. Villa M, Gialitakis M, Tolaini M, Ahlfors H, Henderson CJ, Wolf CR, Brink R, Stockinger B: Aryl hydrocarbon receptor is required for optimal B-cell proliferation. EMBO J 2017, 36:116-128.

20. Barouki R, Coumoul X, Fernandez-Salguero PM: The aryl hydrocarbon receptor, more than a xenobiotic-interacting protein. FEBS Lett 2007, 581:3608-3615.

21. Tijet N, Boutros PC, Moffat ID, Okey AB, Tuomisto J, Pohjanvirta R: Aryl hydrocarbon receptor regulates distinct dioxin-dependent and dioxin-independent gene batteries. Mol Pharmacol 2006, 69:140-153.

22. Swanson HI, Tullis K, Denison MS: Binding of transformed Ah receptor complex to a dioxin responsive transcriptional enhancer: evidence for two distinct heteromeric DNA-binding forms. Biochemistry 1993, 32:12841-12849.

23. Sun YV, Boverhof DR, Burgoon LD, Fielden MR, Zacharewski TR: Comparative analysis of dioxin response elements in human, mouse and rat genomic sequences. Nucleic Acids Res 2004, 32:4512-4523.

24. Davarinos NA, Pollenz RS: Aryl hydrocarbon receptor imported into the nucleus following ligand binding is rapidly degraded via the cytosplasmic proteasome following nuclear export. $J$ Biol Chem 1999, 274:28708-28715.

25. Pollenz Rs: The mechanism of $\mathbf{A H}$ receptor protein down-regulation (degradation) and its impact on $\mathbf{A H}$ receptor-mediated gene regulation. Chem Biol Interact 2002, 141.

26. Chu W-C, Hong W-F, Huang M-C, Chen F-Y, Lin S-C, Liao P-J, Su J-GJ: 1Nitropyrene stabilizes the mRNA of cytochrome $P 450$ 1a1, a carcinogenmetabolizing enzyme, via the Akt pathway. Chem Res Toxicol 2009, 22:1938-1947.

27. Koshakji Rp, Harbison Rd, Bush Mt: Studies on the metabolic fate of [14C]2,3,7,8tetrachlorodibenzo-p-dioxin (TCDD) in the mouse. Toxicol Appl Pharmacol 1984, 73.

28. Rose JQ, Ramsey JC, Wentzler TH, Hummel RA, Gehring PJ: The fate of 2,3,7,8tetrachlorodibenzo-p-dioxin following single and repeated oral doses to the rat. Toxicol Appl Pharmacol 1976, 36:209-226.

29. Phillips DL, Pirkle JL, Burse VW, Bernert JT, Henderson LO, Needham LL: Chlorinated hydrocarbon levels in human serum: effects of fasting and feeding. Arch Environ Contam Toxicol 1989, 18:495-500.

30. Wincent E, Bengtsson J, Mohammadi Bardbori A, Alsberg T, Luecke S, Rannug U, Rannug A: Inhibition of cytochrome P4501-dependent clearance of the endogenous agonist FICZ as a mechanism for activation of the aryl hydrocarbon receptor. Proc Natl Acad Sci U S A 2012, 109:4479-4484.

31. Chen Y, Guillemin GJ: Kynurenine pathway metabolites in humans: disease and healthy States. Int J Tryptophan Res IJTR 2009, 2:1-19.

32. Chuang S-C, Fanidi A, Ueland PM, Relton C, Midttun O, Vollset SE, Gunter MJ, Seck1 MJ, Travis RC, Wareham N, et al.: Circulating biomarkers of tryptophan and the 
kynurenine pathway and lung cancer risk. Cancer Epidemiol Biomark Prev Publ Am Assoc Cancer Res Cosponsored Am Soc Prev Oncol 2014, 23:461-468.

33. Venkateswaran N, Lafita-Navarro MC, Hao Y-H, Kilgore JA, Perez-Castro L, Braverman J, Borenstein-Auerbach N, Kim M, Lesner NP, Mishra P, et al.: MYC promotes tryptophan uptake and metabolism by the kynurenine pathway in colon cancer. Genes Dev 2019, 33:1236-1251.

34. Adams S, Teo C, McDonald KL, Zinger A, Bustamante S, Lim CK, Sundaram G, Braidy $\mathrm{N}$, Brew BJ, Guillemin GJ: Involvement of the kynurenine pathway in human glioma pathophysiology. PloS One 2014, 9:e112945.

35. Rad Pour S, Morikawa H, Kiani NA, Yang M, Azimi A, Shafi G, Shang M, Baumgartner R, Ketelhuth DFJ, Kamleh MA, et al.: Exhaustion of CD4+ T-cells mediated by the Kynurenine Pathway in Melanoma. Sci Rep 2019, 9:12150.

36. Too LK, Li KM, Suarna C, Maghzal GJ, Stocker R, McGregor IS, Hunt NH: Deletion of TDO2, IDO-1 and IDO-2 differentially affects mouse behavior and cognitive function. Behav Brain Res 2016, 312:102-117.

37. Günther J, Däbritz J, Wirthgen E: Limitations and Off-Target Effects of TryptophanRelated IDO Inhibitors in Cancer Treatment. Front Immunol 2019, 10.

38. Guillemin GJ, Smith DG, Kerr SJ, Smythe GA, Kapoor V, Armati PJ, Brew BJ: Characterisation of kynurenine pathway metabolism in human astrocytes and implications in neuropathogenesis. Redox Rep Commun Free Radic Res 2000, 5:108111.

39. Neavin DR, Liu D, Ray B, Weinshilboum RM: The Role of the Aryl Hydrocarbon Receptor (AHR) in Immune and Inflammatory Diseases. Int J Mol Sci 2018, 19.

40. Ramos-García NA, Orozco-Ibarra M, Estudillo E, Elizondo G, Gómez Apo E, Chávez Macías LG, Sosa-Ortiz AL, Torres-Ramos MA: Aryl Hydrocarbon Receptor in PostMortem Hippocampus and in Serum from Young, Elder, and Alzheimer's Patients. Int J Mol Sci 2020, 21:1983.

41. Boutros PC, Moffat ID, Franc MA, Tijet N, Tuomisto J, Pohjanvirta R, Okey AB: Dioxin-responsive AHRE-II gene battery: identification by phylogenetic footprinting. Biochem Biophys Res Commun 2004, 321:707-715.

42. Corre S, Tardif N, Mouchet N, Leclair HM, Boussemart L, Gautron A, Bachelot L, Perrot A, Soshilov A, Rogiers A, et al.: Sustained activation of the Aryl hydrocarbon Receptor transcription factor promotes resistance to BRAF-inhibitors in melanoma. Nat Commun 2018, 9:4775.

- This study demonstrates that under BRAF inhibitor pressure, a small sub-population of persister melanoma cell fuels the relapse due to an AhR suractivation.

43. Kobayashi A, Sogawa K, Fujii-Kuriyama Y: Cooperative interaction between AhR.Arnt and Sp1 for the drug-inducible expression of CYP1A1 gene. J Biol Chem 1996, 271:12310-12316. 
44. Wang F, Hoivik D, Pollenz R, Safe S: Functional and physical interactions between the estrogen receptor Sp1 and nuclear aryl hydrocarbon receptor complexes. Nucleic Acids Res 1998, 26:3044-3052.

45. Wang F, Wang W, Safe S: Regulation of constitutive gene expression through interactions of Sp1 protein with the nuclear aryl hydrocarbon receptor complex. Biochemistry 1999, 38:11490-11500.

46. Yanagida A, Sogawa K, Yasumoto KI, Fujii-Kuriyama Y: A novel cis-acting DNA element required for a high level of inducible expression of the rat $\mathrm{P}-450 \mathrm{c}$ gene. $\mathrm{Mol}$ Cell Biol 1990, 10:1470-1475.

47. Vogel CFA, Sciullo E, Li W, Wong P, Lazennec G, Matsumura F: RelB, a new partner of aryl hydrocarbon receptor-mediated transcription. Mol Endocrinol Baltim Md 2007, 21:2941-2955.

48. Puga A, Barnes SJ, Dalton TP, Chang C y, Knudsen ES, Maier MA: Aromatic hydrocarbon receptor interaction with the retinoblastoma protein potentiates repression of E2F-dependent transcription and cell cycle arrest. J Biol Chem 2000, 275:2943-2950.

49. Kim DW, Gazourian L, Quadri SA, Romieu-Mourez R, Sherr DH, Sonenshein GE: The RelA NF-kappaB subunit and the aryl hydrocarbon receptor $(\mathrm{AhR})$ cooperate to transactivate the c-myc promoter in mammary cells. Oncogene 2000, 19:5498-5506.

50. Tian Y, Ke S, Denison MS, Rabson AB, Gallo MA: Ah receptor and NF-kappaB interactions, a potential mechanism for dioxin toxicity. J Biol Chem 1999, 274:510 515.

51. Klinge CM, Kaur K, Swanson HI: The aryl hydrocarbon receptor interacts with estrogen receptor alpha and orphan receptors COUP-TFI and ERRalpha1. Arch Biochem Biophys 2000, 373:163-174.

52. Ohtake F, Takeyama K, Matsumoto T, Kitagawa H, Yamamoto Y, Nohara K, Tohyama $\mathrm{C}$, Krust A, Mimura J, Chambon $\mathrm{P}$, et al.: Modulation of oestrogen receptor signalling by association with the activated dioxin receptor. Nature 2003, 423:545-550.

53. Roman AC, Benitez DA, Carvajal-Gonzalez JM, Fernandez-Salguero PM: Genome-wide $B 1$ retrotransposon binds the transcription factors dioxin receptor and Slug and regulates gene expression in vivo. Proc Natl Acad Sci U S A 2008, 105:1632-1637.

54. Apetoh L, Quintana FJ, Pot C, Joller N, Xiao S, Kumar D, Burns EJ, Sherr DH, Weiner HL, Kuchroo VK: The aryl hydrocarbon receptor interacts with c-Maf to promote the differentiation of type 1 regulatory T cells induced by IL-27. Nat Immunol 2010, 11:854-861.

55. Gandhi R, Kumar D, Burns EJ, Nadeau M, Dake B, Laroni A, Kozoriz D, Weiner HL, Quintana FJ: Activation of the aryl hydrocarbon receptor induces human type 1 regulatory T cell-like and Foxp3+ regulatory T cells. Nat Immunol 2010, 11:846-853.

56. Monteiro P, Gilot D, Le Ferrec E, Lecureur V, N'diaye M, Le Vee M, Podechard N, Pouponnot C, Fardel $\mathrm{O}$ : AhR- and c-maf-dependent induction of beta7-integrin 
expression in human macrophages in response to environmental polycyclic aromatic hydrocarbons. Biochem Biophys Res Commun 2007, 358.

57. Pot C, Jin H, Awasthi A, Liu SM, Lai C-Y, Madan R, Sharpe AH, Karp CL, Miaw S-C, Ho I-C, et al.: Cutting edge: IL-27 induces the transcription factor c-Maf, cytokine IL-21, and the costimulatory receptor ICOS that coordinately act together to promote differentiation of IL-10-producing Tr1 cells. J Immunol Baltim Md 1950 2009, 183:797-801.

58. Dabir P, Marinic TE, Krukovets I, Stenina OI: Aryl hydrocarbon receptor is activated by glucose and regulates the thrombospondin- 1 gene promoter in endothelial cells. Circ Res 2008, 102:1558-1565.

59. Kimura A, Naka T, Nohara K, Fujii-Kuriyama Y, Kishimoto T: Aryl hydrocarbon receptor regulates Stat1 activation and participates in the development of Th17 cells. Proc Natl Acad Sci U S A 2008, 105:9721-9726.

60. Kimura A, Naka T, Nakahama T, Chinen I, Masuda K, Nohara K, Fujii-Kuriyama Y, Kishimoto T: Aryl hydrocarbon receptor in combination with Stat1 regulates LPSinduced inflammatory responses. $J$ Exp Med 2009, 206:2027-2035.

61. Wu HY, Quintana FJ, da Cunha AP, Dake BT, Koeglsperger T, Starossom SC, Weiner HL: In vivo induction of Tr1 cells via mucosal dendritic cells and AHR signaling. PloS One 2011, 6:e23618.

62. Pot C, Apetoh L, Kuchroo VK: Type 1 regulatory T cells $(\operatorname{Tr} 1)$ in autoimmunity. Semin Immunol 2011, 23:202-208.

63. Veldhoen M, Hirota K, Christensen J, O’Garra A, Stockinger B: Natural agonists for aryl hydrocarbon receptor in culture medium are essential for optimal differentiation of Th17 T cells. J Exp Med 2009, 206:43-49.

64. Esser C: The Aryl Hydrocarbon Receptor in Immunity: Tools and Potential. Methods Mol Biol Clifton NJ 2016, 1371.

65. Jin X, Kim LJY, Wu Q, Wallace LC, Prager BC, Sanvoranart T, Gimple RC, Wang X, Mack SC, Miller TE, et al.: Targeting glioma stem cells through combined BMI1 and EZH2 inhibition. Nat Med 2017, 23:1352-1361.

66. Gautron A, Bachelot L, Quéméner AM, Corre S, Aubry M, Rambow F, Paris A, Tardif N, Leclair HM, Coulouarn C, et al.: Gain-of-function CRISPR screens identify tumorpromoting genes conferring melanoma cell plasticity and therapy-resistance. bioRxiv 2020, doi:10.1101/2020.07.08.193102.

67. Patel AP, Tirosh I, Trombetta JJ, Shalek AK, Gillespie SM, Wakimoto H, Cahill DP, Nahed BV, Curry WT, Martuza RL, et al.: Single-cell RNA-seq highlights intratumoral heterogeneity in primary glioblastoma. Science 2014, 344:1396-1401.

68. Platten M: Driving mesenchymal transition in glioblastoma. Neuro-Oncol 2020, 22. 
69. Rambow F, Rogiers A, Marin-Bejar O, Aibar S, Femel J, Dewaele M, Karras P, Brown D, Chang YH, Debiec-Rychter M, et al.: Toward Minimal Residual Disease-Directed Therapy in Melanoma. Cell 2018, 174:843-855.e19.

- The Marine team performed the first single cell RNA-sequencing experiments from cutaneous melanoma during each phase of the treatment. They highlighted the cell plasticity of melanoma cell subpopulations.

70. Tsoi J, Robert L, Paraiso K, Galvan C, Sheu KM, Lay J, Wong DJL, Atefi M, Shirazi R, Wang X, et al.: Multi-stage Differentiation Defines Melanoma Subtypes with Differential Vulnerability to Drug-Induced Iron-Dependent Oxidative Stress. Cancer Cell 2018, 33:890-904.e5.

- Authors demonstrated the cell plasticity of melanoma cell subpopulations in response to treatment by analyzing 53 melanoma cells lines. They identified four major melanoma subtypes.

71. Wouters J, Kalender-Atak Z, Minnoye L, Spanier KI, De Waegeneer M, Bravo GonzálezBlas C, Mauduit D, Davie K, Hulselmans G, Najem A, et al.: Robust gene expression programs underlie recurrent cell states and phenotype switching in melanoma. Nat Cell Biol 2020, 22:986-998.

- These authors identified the gene regulatory networks defining melanoma subtype and governing subtype switching.

72. Shaffer SM, Emert BL, Reyes Hueros RA, Cote C, Harmange G, Schaff DL, Sizemore AE, Gupte R, Torre E, Singh A, et al.: Memory Sequencing Reveals Heritable SingleCell Gene Expression Programs Associated with Distinct Cellular Behaviors. Cell 2020, 182:947-959.e17.

•• The Raj team developed the MemorySeq, a powerful method for identifying rare, heritable cell expression patterns in cells.

73. Javelaud D, Delmas V, Möller M, Sextius P, André J, Menashi S, Larue L, Mauviel A: Stable overexpression of Smad7 in human melanoma cells inhibits their tumorigenicity in vitro and in vivo. Oncogene 2005, 24.

74. Lee Jh, Shklovskaya E, Lim Sy, Carlino Ms, Menzies Am, Stewart A, Pedersen B, Irvine M, Alavi S, Yang Jyh, et al.: Transcriptional downregulation of MHC class I and melanoma de- differentiation in resistance to PD-1 inhibition. Nat Commun 2020, 11.

- This article showed that TGF- $\beta$ reduces MHC class I expression and is associated with dedifferentiation and anti PD-1 resistance in melanoma.

75. Mantovani A, Dinarello CA, Molgora M, Garlanda C: Interleukin-1 and Related Cytokines in the Regulation of Inflammation and Immunity. Immunity 2019, 50:778795.

76. Morales-Hernández A, González-Rico FJ, Román AC, Rico-Leo E, Alvarez-Barrientos A, Sánchez L, Macia Á, Heras SR, García-Pérez JL, Merino JM, et al.: Alu 
retrotransposons promote differentiation of human carcinoma cells through the aryl hydrocarbon receptor. Nucleic Acids Res 2016, 44:4665-4683.

77. Liu Y, Liang X, Yin X, Lv J, Tang K, Ma J, Ji T, Zhang H, Dong W, Jin X, et al.: Blockade of IDO-kynurenine-AhR metabolic circuitry abrogates IFN- $\gamma$-induced immunologic dormancy of tumor-repopulating cells. Nat Commun 2017, 8:15207.

78. Liu Y, Liang X, Dong W, Fang Y, Lv J, Zhang T, Fiskesund R, Xie J, Liu J, Yin X, et al.: Tumor-Repopulating Cells Induce PD-1 Expression in CD8+ T Cells by Transferring Kynurenine and AhR Activation. Cancer Cell 2018, 33:480-494.e7.

- This article showed that the communication between cancer cells and CD8+ T cells via tryptophan metabolites drives PD-1 upregulation and immune escape.

79. Kaper T, Looger LL, Takanaga H, Platten M, Steinman L, Frommer WB: Nanosensor detection of an immunoregulatory tryptophan influx/kynurenine efflux cycle. PLoS Biol 2007, 5:e257.

80. Opitz CA, Litzenburger UM, Sahm F, Ott M, Tritschler I, Trump S, Schumacher T, Jestaedt L, Schrenk D, Weller M, et al.: An endogenous tumour-promoting ligand of the human aryl hydrocarbon receptor. Nature 2011, 478:197-203.

81. Daillère R, Derosa L, Bonvalet M, Segata N, Routy B, Gariboldi M, Budinská E, De Vries IJM, Naccarati AG, Zitvogel V, et al.: Trial watch : the gut microbiota as a tool to boost the clinical efficacy of anticancer immunotherapy. Oncoimmunology 2020, 9:1774298.

82. Gopalakrishnan V, Spencer CN, Nezi L, Reuben A, Andrews MC, Karpinets TV, Prieto PA, Vicente D, Hoffman K, Wei SC, et al.: Gut microbiome modulates response to anti-PD-1 immunotherapy in melanoma patients. Science 2018, 359:97-103.

83. Mohammadi-Bardbori A, Bengtsson J, Rannug U, Rannug A, Wincent E: Quercetin, resveratrol, and curcumin are indirect activators of the aryl hydrocarbon receptor (AHR). Chem Res Toxicol 2012, 25:1878-1884.

84. Nejman D, Livyatan I, Fuks G, Gavert N, Zwang Y, Geller LT, Rotter-Maskowitz A, Weiser R, Mallel G, Gigi E, et al.: The human tumor microbiome is composed of tumor type-specific intracellular bacteria. Science 2020, 368:973-980.

85. Dehhaghi M, Kazemi Shariat Panahi H, Heng B, Guillemin GJ: The Gut Microbiota, Kynurenine Pathway, and Immune System Interaction in the Development of Brain Cancer. Front Cell Dev Biol 2020, 8.

86. Triplett TA, Garrison KC, Marshall N, Donkor M, Blazeck J, Lamb C, Qerqez A, Dekker JD, Tanno Y, Lu W-C, et al.: Reversal of indoleamine 2,3-dioxygenase-mediated cancer immune suppression by systemic kynurenine depletion with a therapeutic enzyme. Nat Biotechnol 2018, 36:758-764.

- This team developed a KYNU recombinant enzyme which reduces systemic kynurenine levels, thereby improving median survival in melanoma murine models. 
87. Bessede A, Gargaro M, Pallotta Mt, Matino D, Servillo G, Brunacci C, Bicciato S, Mazza Em, Macchiarulo A, Vacca $\mathrm{C}$, et al.: Aryl hydrocarbon receptor control of a disease tolerance defence pathway. Nature 2014, 511.

88. Yan Y, Zhang Gx, Gran B, Fallarino F, Yu S, Li H, Cullimore Ml, Rostami A, Xu H: IDO upregulates regulatory $T$ cells via tryptophan catabolite and suppresses encephalitogenic $\mathbf{T}$ cell responses in experimental autoimmune encephalomyelitis. $J$ Immunol Baltim Md 1950 2010, 185.

89. Nguyen Nt, Kimura A, Nakahama T, Chinen I, Masuda K, Nohara K, Fujii-Kuriyama Y, Kishimoto T: Aryl hydrocarbon receptor negatively regulates dendritic cell immunogenicity via a kynurenine-dependent mechanism. Proc Natl Acad Sci U S A 2010, 107.

90. Campesato LF, Budhu S, Tchaicha J, Weng C-H, Gigoux M, Cohen IJ, Redmond D, Mangarin L, Pourpe S, Liu C, et al.: Blockade of the AHR restricts a Treg-macrophage suppressive axis induced by L-Kynurenine. Nat Commun 2020, 11:4011.

- The first publication publishing hopeful preclinical data with an AhR antagonist from Ikena Oncology (kyn101).

91. Pinto S, Steeneck C, Albers M, Birkel M, Buselic-Wölfel L, Krol H, Anderhub S, Kremoser C, Hoffmann T, Deuschle U: Targeting the IDO1-Kynurenine-AhR pathway for cancer immunotherapy. 2019,

92. Kenison-White J, Wang Z, Sherr DH: The Aryl Hydrocarbon Receptor (AHR) as a Driver of Cancer Immunosuppression. 2018,

93. Mulero-Navarro S, Fernandez-Salguero PM: New Trends in Aryl Hydrocarbon Receptor Biology. Front Cell Dev Biol 2016, 4:45.

94. Opitz CA, Somarribas Patterson LF, Mohapatra SR, Dewi DL, Sadik A, Platten M, Trump S: The therapeutic potential of targeting tryptophan catabolism in cancer. $\mathrm{Br}$ J Cancer 2020, 122:30-44.

- This review summarizes the therapeutic strategies and associated clinical trials based on inhibition of tryptophan catabolism in cancer.

95. Loaiza-Pérez Ai, Kenney S, Boswell J, Hollingshead M, Alley Mc, C H, Hp C, Gc Y, Jb $\mathrm{T}$, Dt V, et al.: Aryl hydrocarbon receptor activation of an antitumor aminoflavone: basis of selective toxicity for MCF-7 breast tumor cells. Mol Cancer Ther 2004, 3.

96. Luzzani GA, Callero MA, Kuruppu AI, Trapani V, Flumian C, Todaro L, Bradshaw TD, Perez AIL: In Vitro Antitumor Effects of AHR Ligands Aminoflavone (AFP 464) and Benzothiazole (5F 203) in Human Renal Carcinoma Cells. J Cell Biochem 2017, 118:4526-4535.

97. Leucci E, Vendramin R, Spinazzi M, Laurette P, Fiers M, Wouters J, Radaelli E, Eyckerman S, Leonelli C, Vanderheyden K, et al.: Melanoma addiction to the long noncoding RNA SAMMSON. Nature 2016, 531:518-522. 
98. Gilot D, Migault M, Bachelot L, Journé F, Rogiers A, Donnou-Fournet E, Mogha A, Mouchet N, Pinel-Marie M-L, Mari B, et al.: A non-coding function of TYRP1 mRNA promotes melanoma growth. Nat Cell Biol 2017, 19:1348-1357.

99. Brennan Jc, He G, Tsutsumi T, Zhao J, Wirth E, Fulton Mh, Denison Ms: Development of Species-Specific Ah Receptor-Responsive Third Generation CALUX Cell Lines with Enhanced Responsiveness and Improved Detection Limits. Environ Sci Technol $2015,49$.

100. Hayashi A, Denison Ms: Development of a novel recombinant cell line for detection and characterization of Ah receptor nuclear translocation in intact cells. Toxicol Vitro Int J Publ Assoc BIBRA 2020, 66.

- The Denison team developed a new sensor to evaluate AhR activation. This in cellulo assay is based on the quantification of AhR nuclear translocation. 


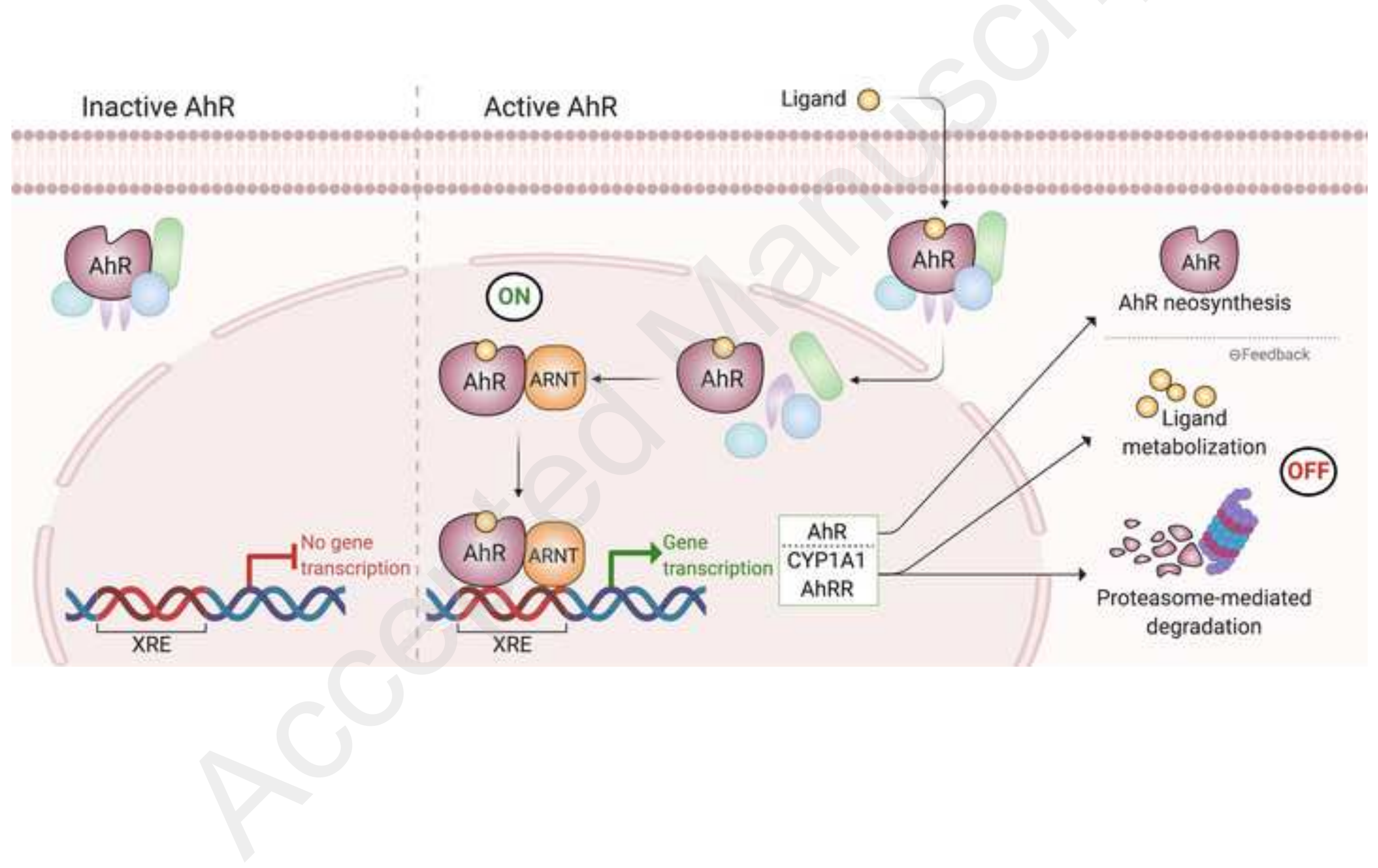




\section{A round of AhR cycle}

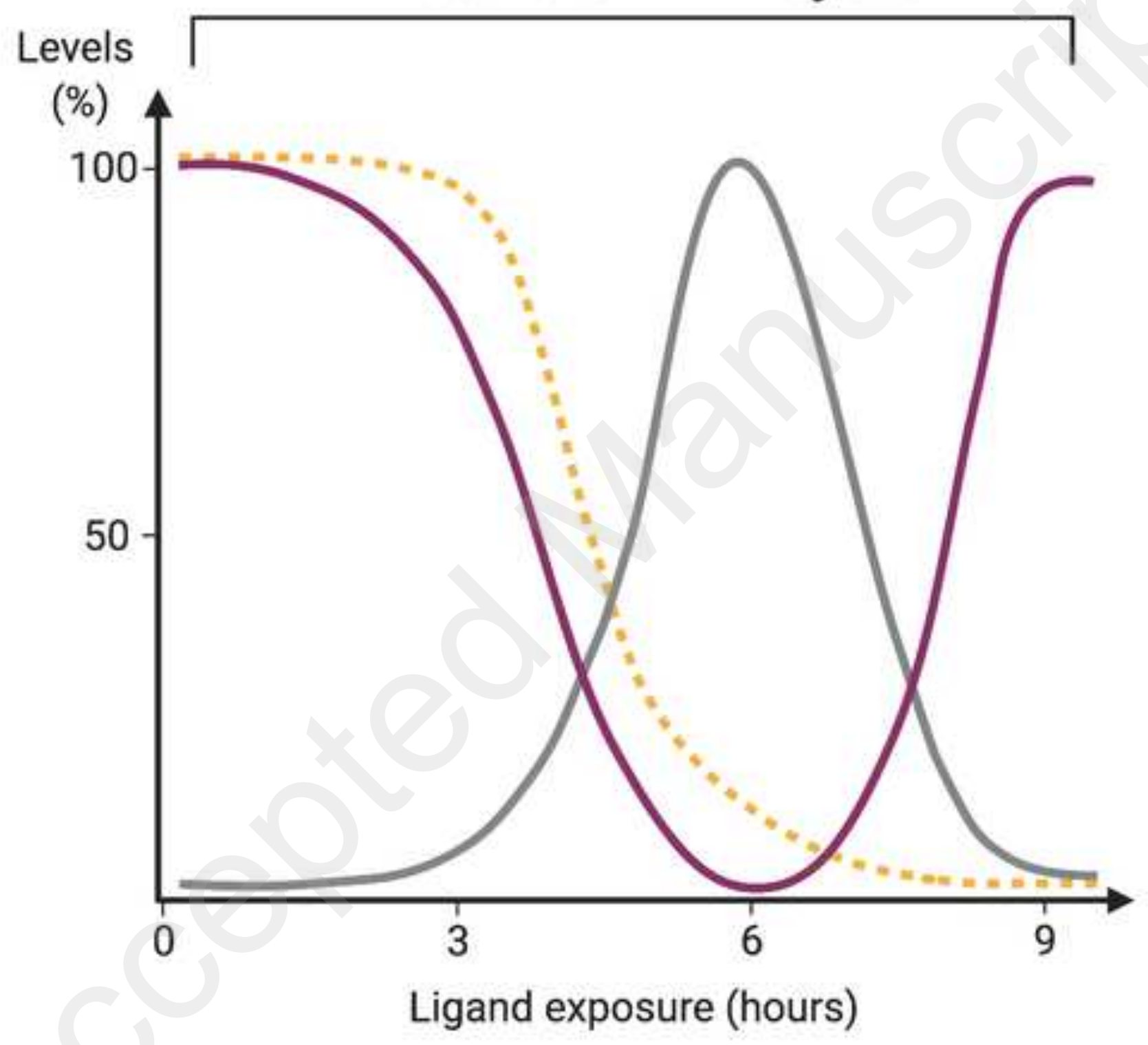

AhR protein CYP1A1 protein Ligand 


\section{AhR Signatures}

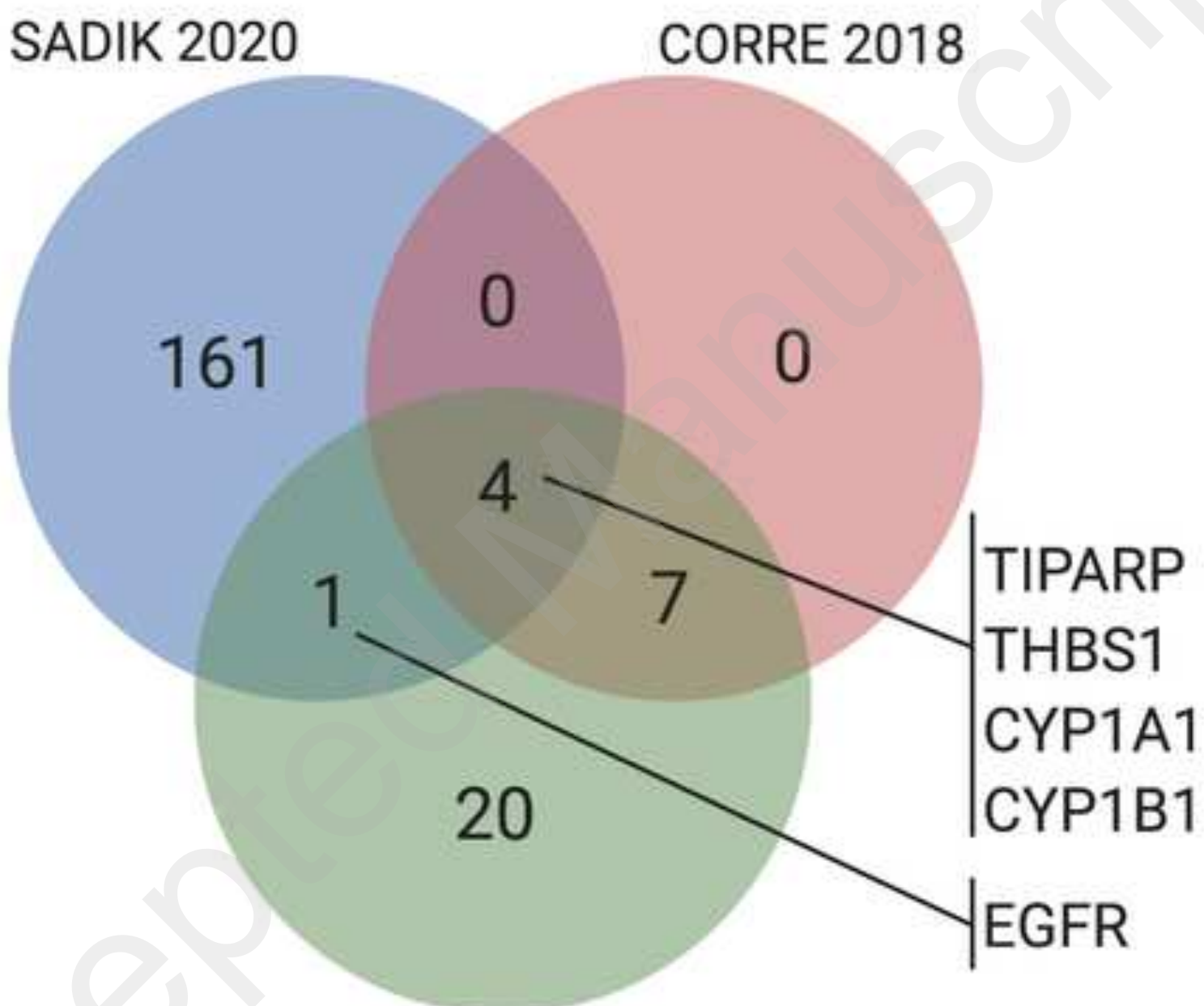

CORRE

(AhR and Signature) 


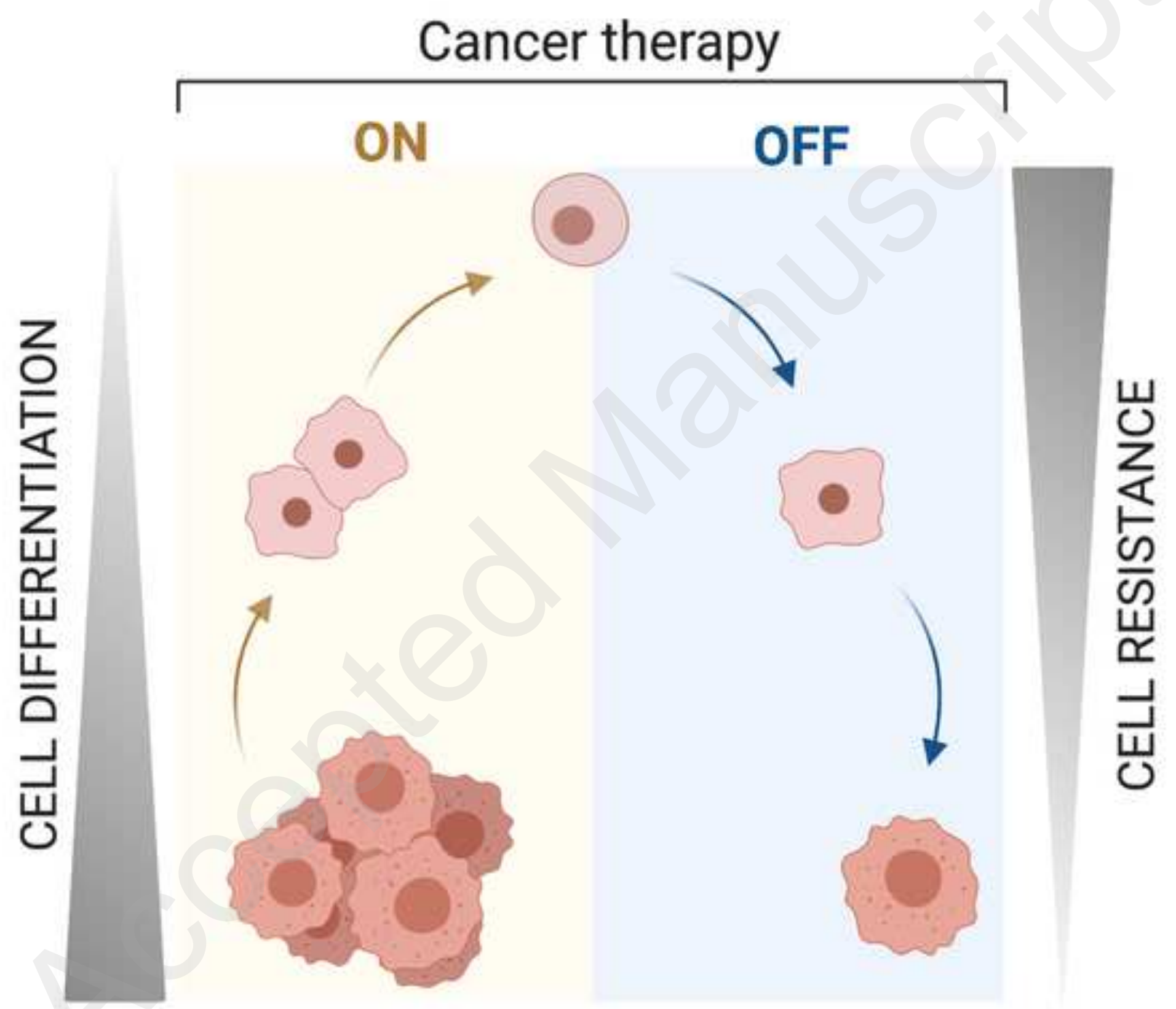

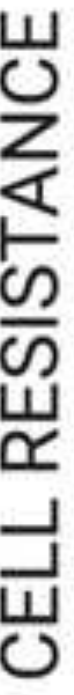




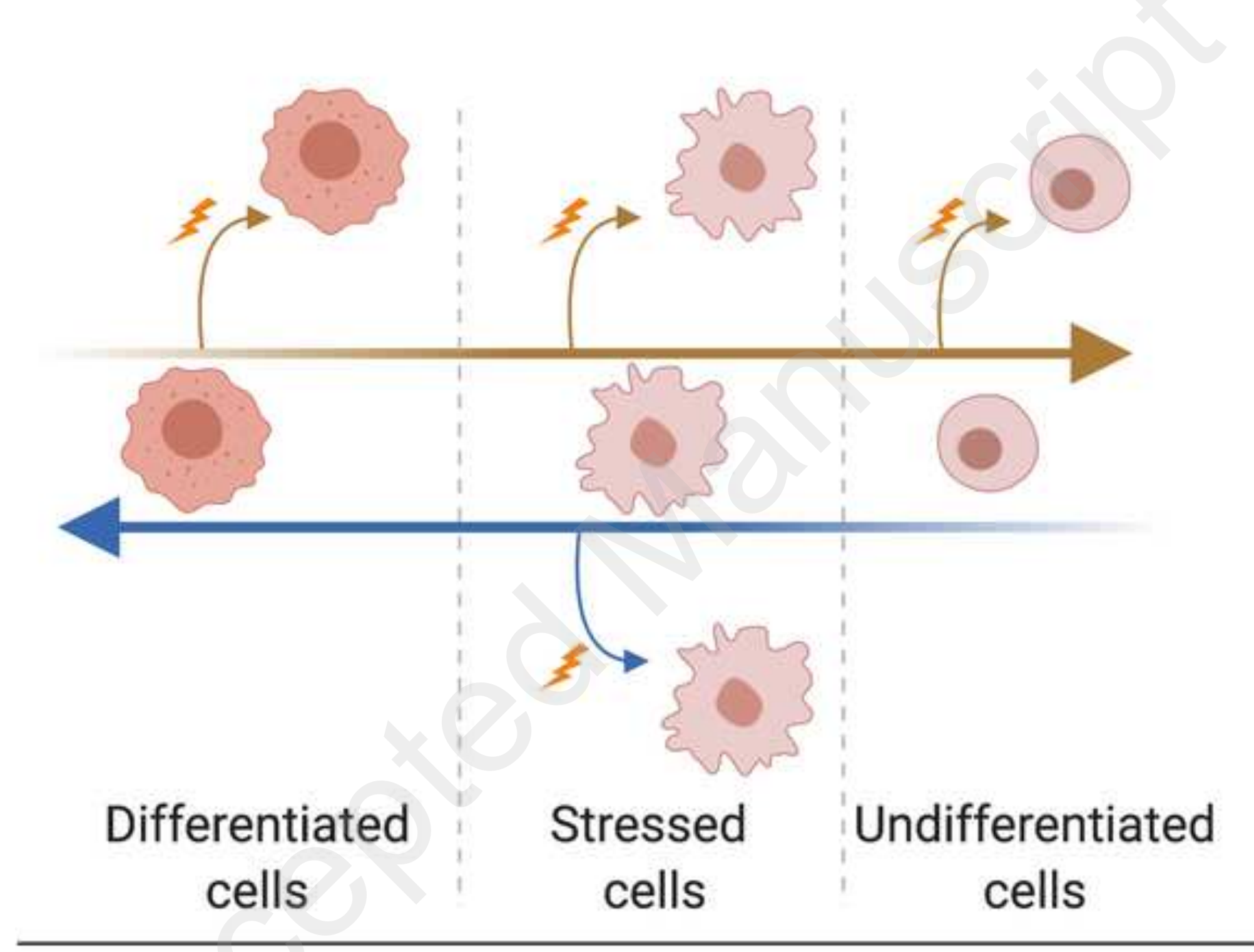

Cancer therapy ON Cancer therapy OFF Genetic alteration

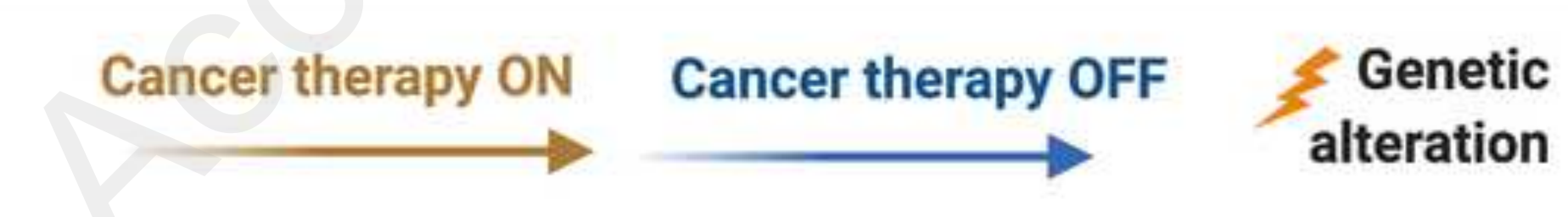

Differentiated cells

.

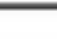

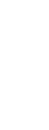

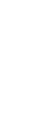




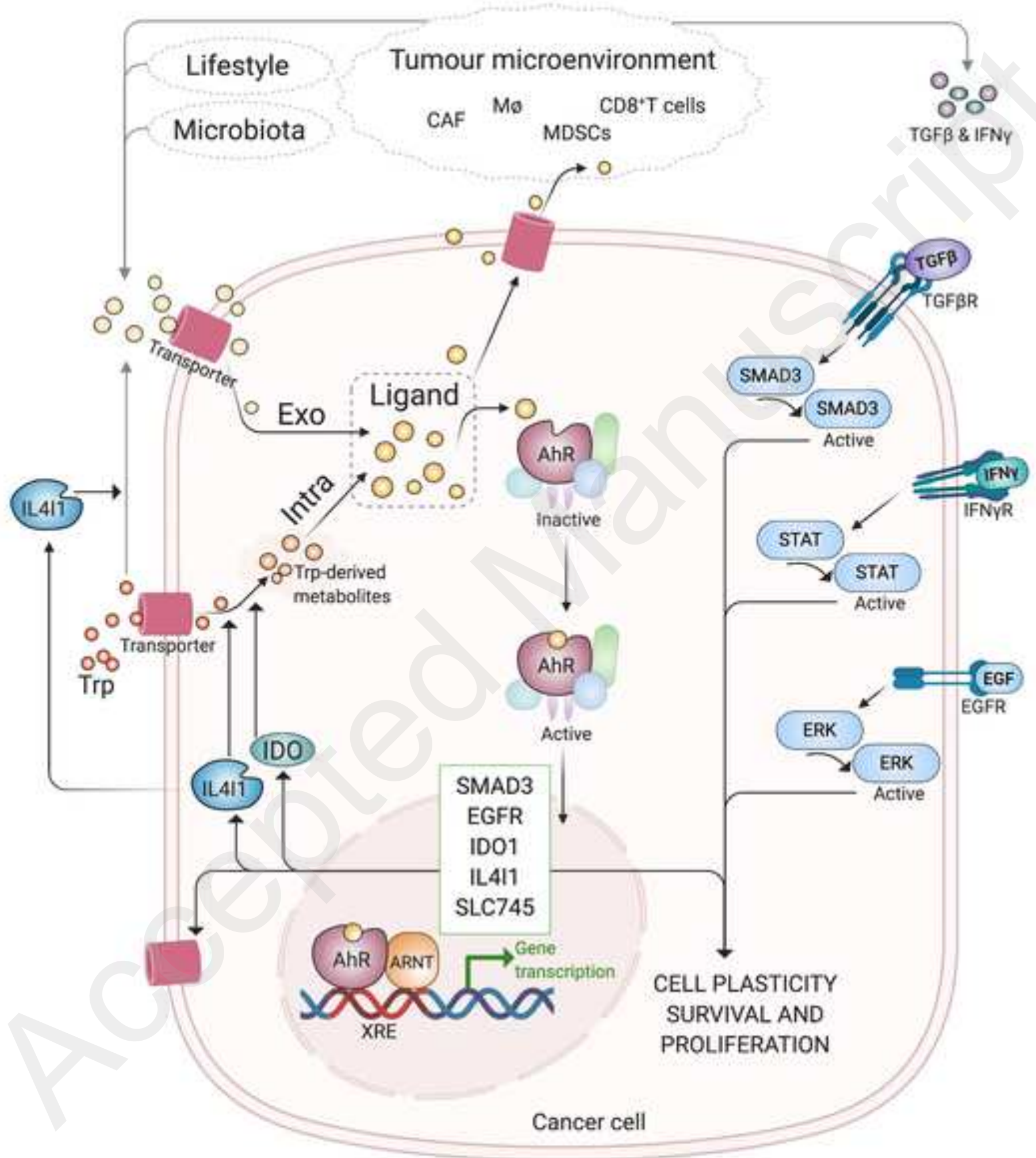




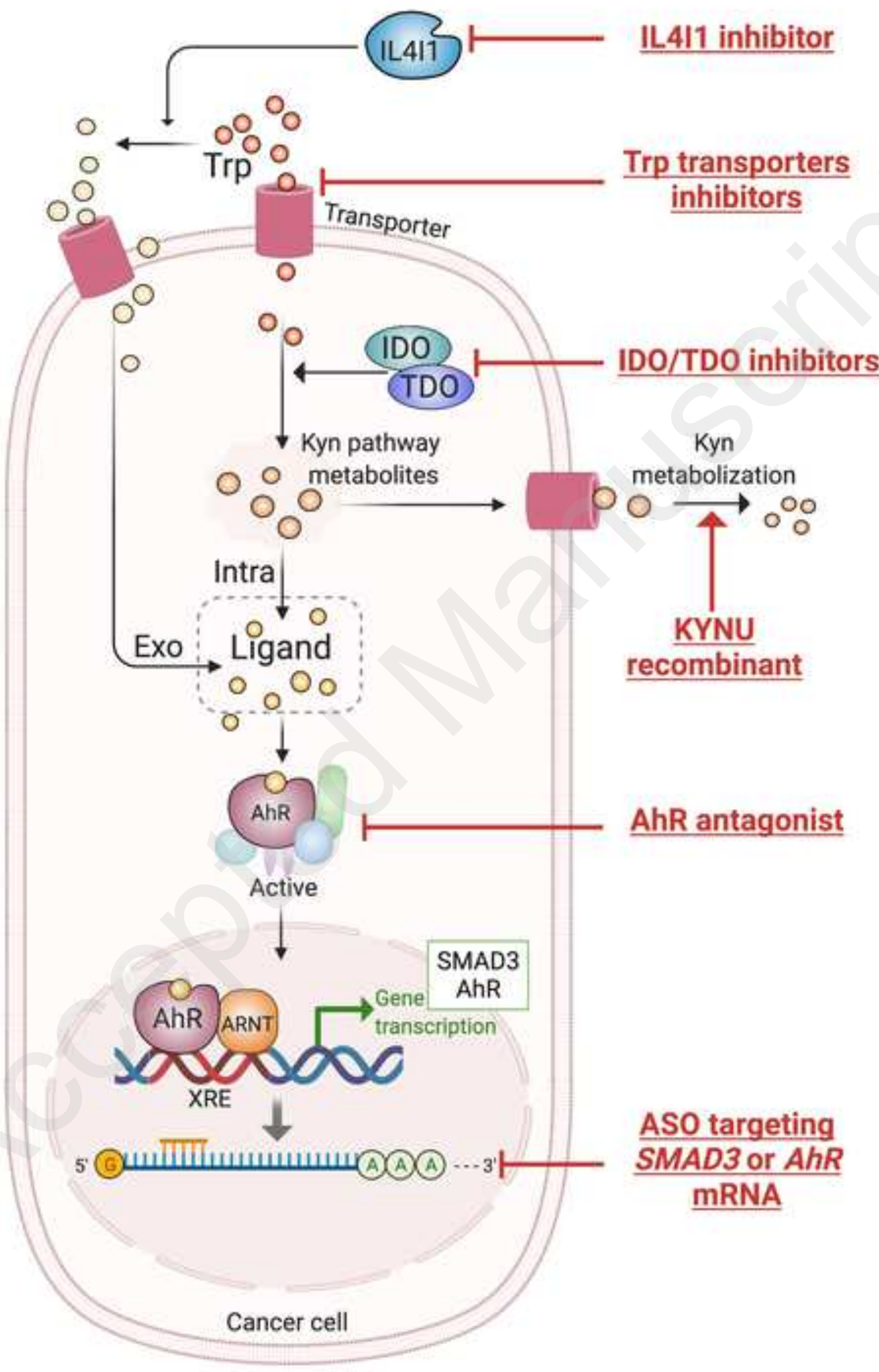

